Original Research Paper

\title{
Study of Supercritical Coal Extraction in Toluene Containing Fluids
}

\author{
${ }^{1,2}$ Peter Nikolayevich Kuznetsov, ${ }^{1}$ Svetlana Mikhaylovna Kolesnikova, \\ ${ }^{1}$ Ludmila Ivanovna Kuznetsova and ${ }^{2}$ Anastasia Valerievna Kazbanova \\ ${ }^{I}$ Institute of Chemistry and Chemical Technology SB, 50-24 Akademgorodok, Krasnoyarsk, 660036, Russia \\ ${ }^{2}$ Siberian Federal University, Russia
}

Article history

Received: 07-10-2015

Revised: 26-02-2016

Accepted: 27-02-2016

Corresponding Author: Peter Nikolayevich Kuznetsov Institute of Chemistry and Chemical Technology SB, 5024 Akademgorodok,

Krasnoyarsk, 660036, Russia Email: monblan.pro@yandex.ru

\begin{abstract}
The conversion of brown coals and sapropelic coal in toluene containing mixtures with co-solvents (water, ethanol and tetralin) was studied under sub- and supercritical conditions within the temperature range of $375-550^{\circ} \mathrm{C}$ and at pressures from 7 to $40 \mathrm{MPa}$. It was found that the extent of coal extraction in the toluene solvent medium, at $400^{\circ} \mathrm{C}$, was significantly increased by the addition of small amounts of hydrogen-donor tetralin or ethanol co-solvents. The extract yield from sapropelic coal reached $79-83 \%$, with the gas yield being small. The effect of process variables on extract yields under sub- and supercritical conditions was monitored. Coal extraction in the toluene-tetralin mixtures was found to depend mainly on the hydrogen donor ability of the tetralin co-solvent irrespective of sub-or supercritical toluene states. According to the composition, the bitumen extracted from coals can be used as a feedstock for pitch production. In the water containing mediums, aside from coal liquefaction, coal methanation, hydrolysis and oxidation reactions occurred resulting in the generation of large amounts of methane, hydrogen and carbon dioxide.
\end{abstract}

Keywords: Coals, Toluene, Co-Solvent, Extract, Supercritical Conditions

\section{Introduction}

The non-fuel use of coals includes mainly the high temperature carbonization of bituminous and sub bituminous coals to make metallurgical coke. This process produces coal tar as a by-product. At present, these highly aromatic tars remain a principal pitch source for the production of high quality electrodes for the increasingly developing aluminum industry but also have a wide array of other applications. However, coke production has been decreased worldwide and is projected to decline further due to decreasing demand in the metallurgical industry. This is due to improvements in furnace technology, as well as the steady shift from traditional furnace setups to electric furnaces and the use of pulverized coal instead of coke. The future of the coal tar production thus far seems dim, despite a growing demand in both the aluminum industry and in many other industries for the production of modern highvalue-added products. These differently directed trends in tar demand in the aluminum industry and in tar production in the metallurgical industry are faced with the problem of needing to search.
Different high boiling fractions from petroleum processing are considered as an alternative feedstock (Perez et al., 2003). However, direct coal liquefaction in solvents, or some variant of it, seems to be the most reliable approach to resolve this issue. The polycyclic aromatic nature of coals is a key consideration in making coals an attractive feedstock for pitch-like products. In addition to conventional transportation fuels use, the non-volatile aromatic liquid residues could be used as a feedstock for non-fuel applications, for pitch production in particular (Hu et al., 1998; Cheng et al., 2012; Rahman et al., 2013). The problems which limit the efficiency of current coal conversion processes are not necessary amenable to a solution using conventional solvents, or other established chemical conversion concepts. The application of supercritical fluids for the extraction of naturally occurring polycondensed aromatics from the coal matrix would be one of the most effective and selective process for the production of pitch-like products (Kolak and Burruss, 2014; Sun et al., 2014; Lifshits et al., 2012). The supercritical fluids have an increased dissolving power, which is close to that for liquids, much low viscosity and much high diffusion 
coefficients, close to those of gases. They are considered as solvents which enhance both reagent access to interior organic moiety and product removal from microporous coal residuum.

Various organic substances (aliphatic and aromatic hydrocarbons, alcohols and heterocyclic compounds) were used as solvents (Garcia et al., 2004; Torrente and Galán, 2010; Owczarek and Blazej, 2003; Zhao et al., 2010; Kolak and Burruss, 2014; Sun et al., 2014; Lifshits et al., 2012; Guo and Jin, 2013). Tetralin exhibits usually high efficiency due to hydrogen donor ability (Adschiri et al., 1996). Water is a unique solvent in terms of abundance and environmental and technological safety $\left(T \mathrm{c}=374^{\circ} \mathrm{C}, P \mathrm{c}=21.8 \mathrm{MPa}\right.$ and $\left.\rho_{c}=0.322 \mathrm{~g} / \mathrm{cm}^{3}\right)$ (Kashimura et al., 2004; Han et al., 2015; Wu et al., 2009). It has been shown to stimulate the cleavage of ester bonds (Hu et al., 1998; Bermejo et al., 2004) and thus provide a deep conversion of organic matter from coal. Toluene is of particular interest to technology because it is an abundant component of low-boiling fractions obtained in various coal conversion processes and has an easily attainable critical temperature $\left(318.6^{\circ} \mathrm{C}\right)$, pressure $(4.11$ $\mathrm{MPa})$ and density $\left(0.292 \mathrm{~g} / \mathrm{cm}^{3}\right)$ (Torrente and Galán, 2010; Park et al., 2007; Owczarek and Blazej, 2003; Hourcade et al., 2007). However the extent of coal extraction in toluene media was rather low.

It should be noted that Supercritical Fluid Extraction (SCFE) involves the application of elevated pressure. This shortcoming can be compensated through better control of the conversion to the desired products and through the possibility of overcoming the conventional problems in the traditional processes related to the difficulties in solid-liquid separation using filtration and vacuum distillation. This is especially problematic for the production of non-volatile and viscous coal pitch with very little ash content (less than 0.1-0.3 wt\%). In SCFE, the ashless extract can be easily separated by simple depressurization.

The objective of this paper was to compare the yields of products during supercritical extraction of brown coals and sapropelic coal in the medium of toluene fluid and in toluene mixtures with ethanol, tetralin and water co-solvents.

\section{Materials and Methods}

The samples used in this study consisted of brown coals taken from the Borodino deposit in the KanskAchinsk Basin, Kangalas and Chaidakh deposits in the Lena Basin and a sample of sapropelic coal from the Budagovsky deposit in the Irkutsk basin. The results of the ultimate analysis of coals are given in Table 1 and 2. The data show that the coals differed depending on the composition of both organic matter and mineral constituents. Sapropelic coal differed with a high content of hydrogen and Borodino brown coal contained more calcium in the mineral matter.

The supercritical extraction of coals was performed in a rotating $250 \mathrm{~mL}$ autoclave. A $15 \mathrm{~g}$ coal sample and $30 \mathrm{~g}$ solvent were loaded in the autoclave. Pure toluene and hybrid mixtures with small amounts of tetralin, ethanol and water additives were used as the solvents. The charged autoclave was purged with argon to remove any air. The autoclave was heated at a rate of $10 \mathrm{~K} / \mathrm{min}$ up to the required temperature in the given range of 375 to $550^{\circ} \mathrm{C}$. The reaction time measured for each given specified temperature was $1 \mathrm{~h}$. The autogenous pressure in the autoclave during the reaction was measured by a manometer.

After completion of the reaction and cooling of the autoclave, the volume and the composition of the gases produced were measured and solid and liquid products were removed from the autoclave to a filter. The total conversion of coal was defined as conversion to toluenesoluble matter plus co-produced water and gas and was expressed as $w t \%$ of dry ash free matter of feed coal. It was determined by exhaustively extracting the solid reaction residue with boiling toluene in Soxhlet apparatus, determining its mineral matter content by ashing and using the equation:

$$
\text { conversion, } \%=\left[1-\left(\mathrm{A}_{1}^{d} / \mathrm{A}_{2}^{d}\right)\right] /\left[1-0.01 \mathrm{~A}_{1}^{d}\right]
$$

where, $A^{d}{ }_{1}$ and $A^{d}{ }_{2}$ represent respectively the mineral matter (ash) contents of the dry feed coal and the solid toluene-insoluble reaction residue.

Table 1. Composition of brown coals

\begin{tabular}{|c|c|c|c|c|c|c|c|}
\hline \multirow[b]{2}{*}{ Basin deposit } & \multirow[b]{2}{*}{ Coal type } & \multirow[b]{2}{*}{$A^{d}(\mathrm{wt} . \%)$} & \multicolumn{5}{|c|}{ Ultimate analysis (wt.\%) on a daf basis } \\
\hline & & & $\mathrm{C}$ & $\mathrm{H}$ & $\mathrm{N}$ & $\mathrm{S}$ & $\mathrm{O}$ \\
\hline Borodino & Brown & 4.9 & 71.9 & 4.8 & 1.0 & 0.4 & 21.9 \\
\hline Chaidakh & Brown & 13.3 & 75.0 & 5.2 & 0.9 & 0.5 & 18.4 \\
\hline Kangalas & Brown & 8.0 & 71.1 & 5.6 & 1.0 & 0.5 & 21.8 \\
\hline Budagovsky & Sapropelite & 21.6 & 73.0 & 9.1 & 1.0 & 0.7 & 16.2 \\
\hline
\end{tabular}

Table 2. Concentration levels of the main components of brown coal ashes (wt.\%)

\begin{tabular}{lccccccc}
\hline Coal & $\mathrm{SiO}_{2}$ & $\mathrm{Al}_{2} \mathrm{O}_{3}$ & $\mathrm{CaO}$ & $\mathrm{MgO}$ & $\mathrm{Fe}_{2} \mathrm{O}_{3}$ & $\mathrm{Na}_{2} \mathrm{O}$ & $\mathrm{K}_{2} \mathrm{O}$ \\
\hline Borodino & 52.0 & 6.0 & 25.0 & 5.0 & 6.0 & 0.3 & 0.3 \\
Chaidakh & 49.1 & 21.2 & 13.0 & 1.2 & 8.0 & - & - \\
Kangalas & 53.0 & 15.0 & 17.0 & 3.0 & 7.0 & 2.0 & 0.6 \\
\hline
\end{tabular}


This procedure has been widely employed in laboratory studies of liquefaction. However, in our work the procedure was also specifically verified by some controlling experiments in which special attention was given to the quantitative removal of reaction products from the autoclave. The total conversion of coal in this case was also determined based on decrease in the weight content of organic matter in the tolueneinsoluble residue (i.e., dry ash free coal residue) as compared to its content in the coal loaded. The conversions evaluated by these two procedures were found to be within $\pm 1.5 \%$ in all cases.

The yield of extract product was calculated by difference between total coal conversion and the yield of gaseous products. The composition of extract products was characterized by elemental analysis and by IR-FT spectroscopy. Gaseous products were analyzed by a gas chromatograph.

\section{Results}

The yield of bitumen extracted from brown coals by boiling toluene in a Soxhlet apparatus did not exceed 2 (wt.\%). Shown in Table 3 is the data from the extraction of brown coal and a sapropelic coal sample in pure toluene fluid under supercritical conditions. One can see that the yield of extracted products increased to 24-28 (wt.\%) at $400^{\circ} \mathrm{C}$ and $15-16 \mathrm{MPa}$. The sapropelic coal showed more extract yield of 64 (wt.\%).

The addition of $15 \%$ co-solvents, such as tetralin, ethanol and water to toluene allowed the extract yields to be significantly increased (Fig. 1). Chaidakh brown coal showed higher conversion as compared to Borodino coal. Low extractability of the latter may be due to enhanced amount of calcium which was found (Kuznetsov et al., 1997) to be a strong cross-linking agent in organic coal matter resulting in restricted accessibility for the solvent molecules. Among the coals used, sapropelic one exhibited higher reactivity; the extract yield attained was $80-83 \%$. For all the coals, ethanol was the most effective co-solvent due to hydrogen-donor and alkylating abilities.

\section{Discussion}

The experiments were carried out to compare the effects of subcritical and supercritical conditions on the efficacy of tetralin-toluene solvent. Shown in Fig. 2 is the data relating to Borodino brown coal extraction at $400^{\circ} \mathrm{C}$ using toluene-tetralin mixtures depending on toluene vapor density, with a constant tetralin vapor density set at $0.07 \mathrm{~g} / \mathrm{cm}^{3}$. One can see that the addition of a small amount of tetralin to the toluene solvent allowed the yield of extract to be increased from 22-24 to $37-38 \%$. It is important to note that the increase in the toluene density from $0.144 \mathrm{~g} / \mathrm{cm}^{3}$ (subcritical conditions) to $0.350 \mathrm{~g} / \mathrm{cm}^{3}$ (supercritical conditions) and the total pressure in the autoclave from 7.0 to 12.5 $\mathrm{MPa}$, hardly affected coal conversion and yields of extract and gases. This means that the conversion of brown coal in the toluene-tetralin mixtures was controlled mainly by the presence of tetralin co-solvent irrespective of sub- or supercritical toluene states. Hydrogen-donation from the tetralin molecules to coal radicals and their subsequent extraction in the toluene media is the main cause of this effect.
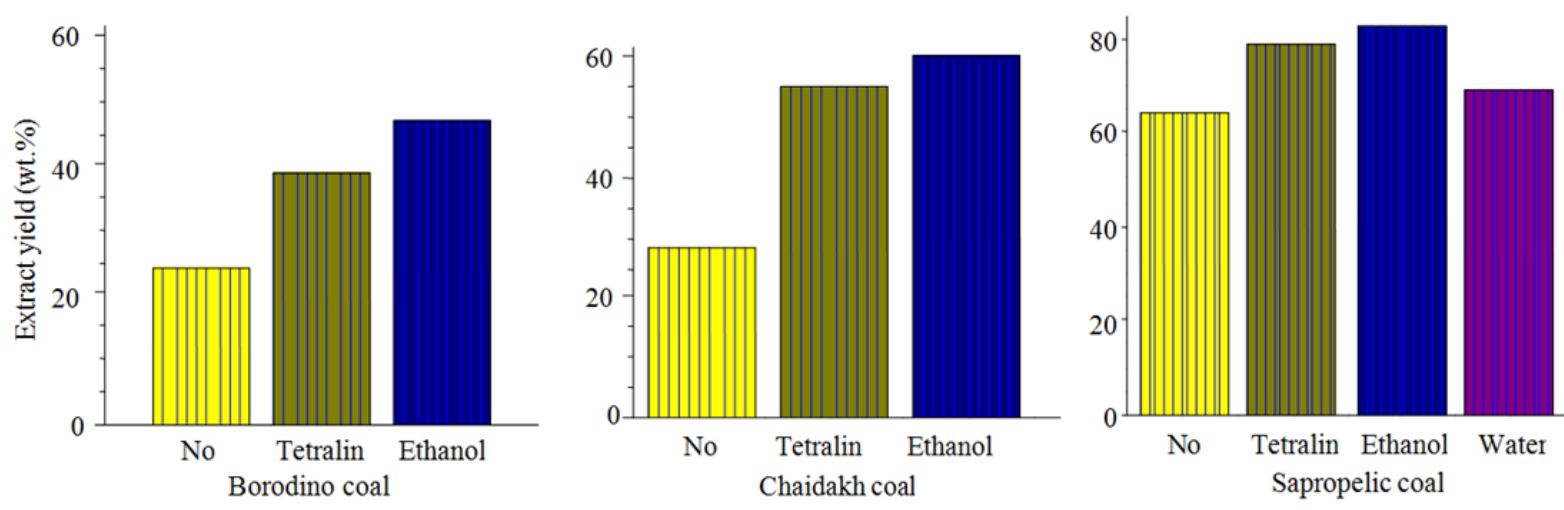

Fig. 1. The effect of co-solvents on the extraction of brown and sapropelic coals in toluene fluid at $400^{\circ} \mathrm{C}$

$\underline{\text { Table 3. Coal extraction in toluene fluid under supercritical conditions }\left(400^{\circ} \mathrm{C} \text {, toluene vapor density of } 0.40 \mathrm{~g} / \mathrm{cm}^{3}\right)}$

\begin{tabular}{|c|c|c|c|c|c|c|}
\hline \multirow[b]{2}{*}{ Deposit } & \multirow{2}{*}{$\begin{array}{l}\text { Reaction } \\
\text { pressure, } \mathrm{MPa}\end{array}$} & \multirow{2}{*}{$\begin{array}{l}\text { Coal } \\
\text { conversion (wt.\%) }\end{array}$} & \multicolumn{3}{|c|}{ Product yield (wt.\%) on daf coal } & \multirow{2}{*}{$\begin{array}{l}A^{d} \text { of toluene } \\
\text { insolubles } \\
(\text { wt. } \% \text { ) }\end{array}$} \\
\hline & & & Extract & Gas & Toluene insolubles & \\
\hline Borodino & 15 & 26.7 & 24 & 2.7 & 73.3 & 6.6 \\
\hline Chaidakh & 16 & 30.8 & 28 & 2.8 & 69.2 & 18.1 \\
\hline Kangalas & 16 & 31.0 & 28 & 3.0 & 69.0 & 11.2 \\
\hline Budagovsky & 13 & 67.0 & 64 & 3.0 & 33.0 & 43.4 \\
\hline
\end{tabular}


The solvent-free extracts were produced by using vacuum distillation of the toluene-tetralin solvent. The chemical composition of the extracts produced from different coals is shown in Table 4. One can see that the sapropelic extract was enriched with hydrogen when compared to the brown coals extracts. The low $\mathrm{H} / \mathrm{C}$ atomic ratio for the brown coal extracts indicated more aromatic nature which is preferred for the production of pitch.

Figure 3 shows the IR-FT spectra for the solvent-free extracts from Borodino and Chaidakh coals. The spectra show absorption bands in the regions of 2820-2980 and $1378-1458 \mathrm{~cm}^{-1}$ (stretching and bending vibrations of saturated $\mathrm{C}-\mathrm{H}$ bonds, respectively), which indicates the presence of saturated hydrocarbons in the extracts. The bands observed in $3020-3030 \mathrm{~cm}^{-1}$ (stretching vibrations of $\mathrm{C}-\mathrm{H}$ bonds in the aromatic rings), $1600 \mathrm{~cm}^{-1}$ (skeletal vibrations of aromatic rings) and $700-900 \mathrm{~cm}^{-1}$ (out-ofplane vibrations of $\mathrm{C}-\mathrm{H}$ bonds in the aromatic rings) are determined by the presence aromatic compounds. Estimates of the ratios of the band intensities in the regions of 3020-3030 and 2820-2980 $\mathrm{cm}^{-1}$ indicated that the aromatic structures contain at least $14-16 \%$ of hydrogen. Judging from the nature of the spectrum in the region of 700-900 $\mathrm{cm}^{-1}$ with the most intense band at $822 \mathrm{~cm}^{-1}$, the aromatic rings are characterized by an average degree of substitution (or of condensation).

Absorption bands at $3300-3400 \mathrm{~cm}^{-1}$ and in the region of $1000-1300 \mathrm{~cm}^{-1}$ are determined by the presence of a certain amount of oxygen-containing compounds (mostly phenols may ethers and esters) in the extracts, as well. In general, it can be noted that the extracts obtained from Borodino and Chaidakh brown coals have similar elemental and molecular composition.

Table 5 gives the data on the extraction of coals in the aqueous medium at different temperatures. Again sapropelic coal showed a much higher extraction yield compared to brown coals. Its conversion at $400^{\circ} \mathrm{C}$ under subcritical condition was as high as $60 \%$. The conversions of brown coals at both sub- and supercritical conditions were no more than $30 \%$.

The increase in the reaction temperature to $550^{\circ} \mathrm{C}$ resulted in an increase in the conversion of Kangalas coal to $51-52 \%$, with the reaction pressure attaining $40 \mathrm{MPa}$. Under these conditions, a lot of gases were produced (47.8-53.1\% based on daf coal), their yield being close to or even exceeded that of total coal conversion. This means that gaseous products were generated not only from the coal matter but also from the water.

Table 6 shows the composition of gaseous products. At high temperature $\left(550^{\circ} \mathrm{C}\right)$ with low water vapor, methane and hydrogen fuel gases were predominantly generated (66.7-74.4\%), whereas mainly carbon dioxide (78.5-81.5\%) was produced at a low reaction temperature with high water vapor. Taking these data into account the yields of gaseous products were recalculated based on carbon balance and the percentage of coal carbon converted into carbon containing gases $\left(\mathrm{CH}_{4}, \mathrm{CO}_{2}\right.$ and $\left.\mathrm{CO}\right)$ was thus derived. This allowed for the percentage of coal converted into extract to be determined. The recalculated data in Table 5 (in parentheses) show that, at $550^{\circ} \mathrm{C}$, more than half of coal carbon matter was converted into gaseous products.

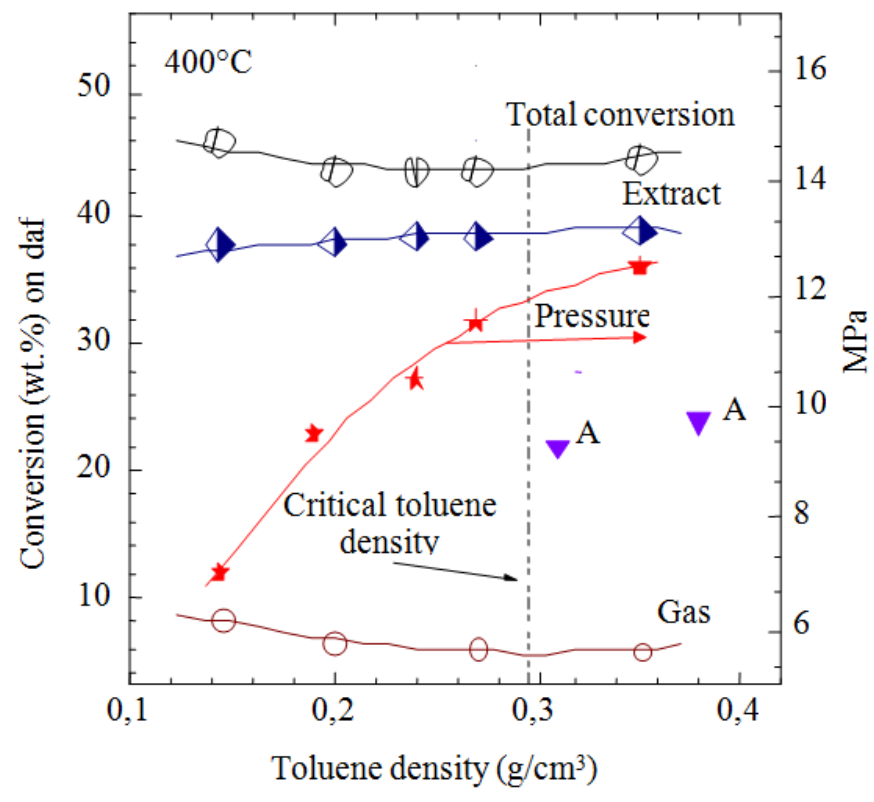

Fig. 2. The conversion of Borodino brown coal at $400^{\circ} \mathrm{C}$ in toluene-tetralin mixtures depending on the toluene vapor density with a constant tetralin vapor density of $0.07 \mathrm{~g} / \mathrm{cm}^{3}$. The symbol A at the inverse triangle point denotes the extract yield in a single supercritical toluene. The dashed line in the Figure indicates a critical toluene density 


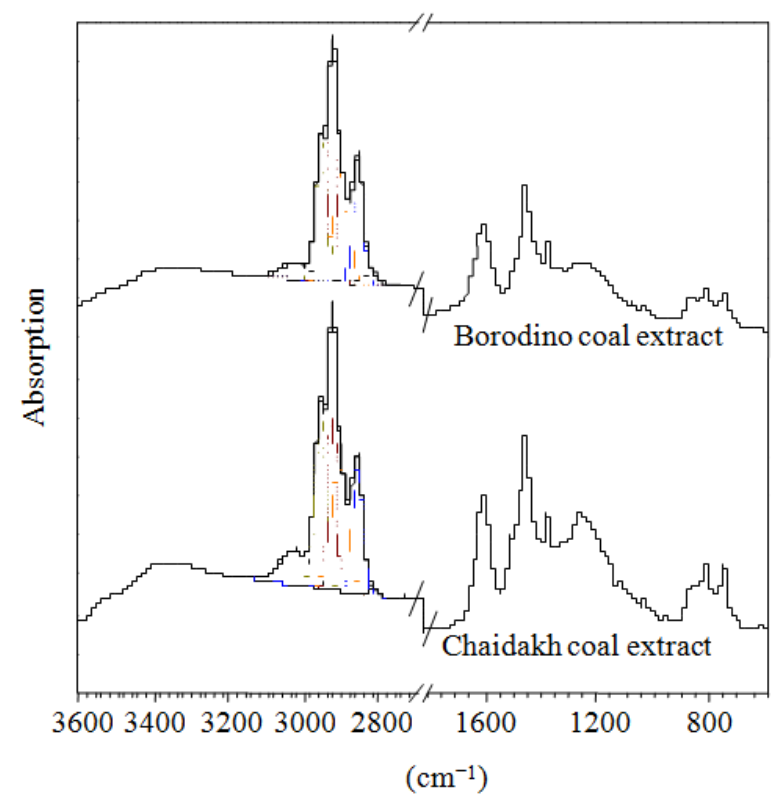

Fig. 3. IR-FT spectra for solvent-free extracts produced from Borodino and Chaidakh coals

Table 4. The element composition of solvent-free extracts produced from different coals

\begin{tabular}{|c|c|c|c|c|c|c|}
\hline \multirow[b]{2}{*}{ Coal } & \multicolumn{6}{|c|}{ Ultimate analysis (wt.\%) } \\
\hline & $\mathrm{C}$ & $\mathrm{H}$ & $\mathrm{N}$ & $\mathrm{S}$ & $\mathrm{O}$ & $\mathrm{H} / \mathrm{C}$ atomic \\
\hline Borodino & 86.2 & 7.6 & 0.3 & 0.3 & 5.6 & 1.06 \\
\hline Chaidakh & 85.4 & 7.7 & 0.7 & 0.3 & 5.9 & 1.10 \\
\hline Budagovsky & 85.3 & 8.8 & 1.0 & 0.4 & 4.5 & 1.23 \\
\hline
\end{tabular}

Table 5. The extraction of brown and sapropelic coals in the aqueous medium

\begin{tabular}{lllllll}
\hline & $\begin{array}{l}\text { Water vapor } \\
\text { density }\left(\mathrm{g} / \mathrm{cm}^{3}\right)\end{array}$ & $\begin{array}{l}\text { Temperature } \\
\left({ }^{\circ} \mathrm{C}\right)\end{array}$ & $\begin{array}{l}\text { Reaction } \\
\text { pressure, MPa }\end{array}$ & $\begin{array}{l}\text { Coal conversion } \\
(\text { wt.\%) }\end{array}$ & $\begin{array}{l}\text { Yield (wt.\%) on daf coal } \\
---- \text { Gas }^{*}\end{array}$ & Solubles* \\
\hline Budagovsky & 0.120 & 400 & 24 & 60 & - & - \\
Chaidakh & 0.120 & 400 & 25 & 30 & - & - \\
Borodino & 0.322 & 375 & 22 & 10 & $15.0(6.4)$ & $-(3.6)$ \\
Borodino & 0.380 & 410 & 35 & 24 & $21.5(9.1)$ & $2.5(14.9)$ \\
Kangalas & 0.380 & 400 & 31 & 25 & $20.8(8.7)$ & $4.2(16.3)$ \\
Kangalas & 0.130 & 550 & 29 & 52 & $47.8(29.1)$ & $4.2(22.9)$ \\
Kangalas & 0.170 & 550 & 40 & $53.1(30.9)$ & $-(20.1)$ \\
\hline
\end{tabular}

*Shown in parentheses are the values recalculated based on a carbon balance in gaseous products

Table 6 . The composition of gaseous products from brown coal conversion in the aqueous medium

\begin{tabular}{llllllll}
\hline & & & & & \\
& Water vapor \\
Depsity $\left(\mathrm{g} / \mathrm{cm}^{3}\right)$ & $\begin{array}{l}\text { Temperature } \\
\left({ }^{\circ} \mathrm{C}\right)\end{array}$ & $-\mathrm{CH}_{4}$ & $\mathrm{CO}$ & $\mathrm{CO}_{2}$ & $\mathrm{H}_{2}$ & other \\
\hline Borodino & 0.322 & 375 & 5.6 & 4.0 & 81.5 & 6.8 & 1.8 \\
Borodino & 0.380 & 410 & 13.4 & 2.9 & 78.5 & 5.0 & 0.2 \\
Kangalas & 0.130 & 550 & 57.9 & 0.8 & 23.0 & 16.5 & 1.8 \\
Kangalas & 0.170 & 550 & 53.9 & 0.7 & 29.4 & 12.8 & 3.2 \\
\hline
\end{tabular}

Table 7. Coal conversion in the mixture of supercritical toluene with water additive $\left(440^{\circ} \mathrm{C}\right.$, toluene and water vapor densities were 0.36 and $0.06 \mathrm{~g} / \mathrm{cm} 3$, respectively)

\begin{tabular}{|c|c|c|c|c|}
\hline \multirow[b]{2}{*}{ Deposit } & \multirow[b]{2}{*}{ Reaction pressure, $\mathrm{MPa}$} & \multirow[b]{2}{*}{ Coal conversion (wt.\%) } & \multicolumn{2}{|c|}{ Yield (wt.\%) on daf coal } \\
\hline & & & gas & extract \\
\hline Budagovsky & 28 & 70 & - & - \\
\hline Chaidakh & 29 & 48 & - & - \\
\hline Borodino & 32 & 31 & 14.7 & 16.3 \\
\hline Kangalas & 29 & 41 & 13.9 & 27.1 \\
\hline
\end{tabular}


In the mixture of supercritical toluene with $15 \%$ water, the coals were also converted mainly into $\mathrm{CH}_{4}$ and $\mathrm{H}_{2}$ at $550^{\circ} \mathrm{C}$. A dramatic decrease in the yields of gaseous products was observed at lower temperature of $440^{\circ} \mathrm{C}$ (Table 7). The gas yields from the Borodino and Kangalas coals were $13.9-14.7 \%$, with the yields of extracts being $16.3-27.1 \%$.

Special experiments using a toluene-water mixture without the addition of coal to the autoclave were carried out at $440^{\circ} \mathrm{C}$ to determine whether the gases originated from the coal or from the solvent (from toluene or water). It was found that few gases were produced in this case without coal (by a factor of 20 compared to that with coal). Mainly $\mathrm{CO}_{2}(43.5 \%)$ and $\mathrm{H}_{2}(42.1 \%)$ were present in the gaseous products, with the content of $\mathrm{CO}$ being much less (14.4\%). No $\mathrm{CH}_{4}$ was detected. No products from toluene destruction (benzene, in particular) were observed in the liquid products. This suggests that in the presence of a water co-solvent under the conditions studied, toluene was not subjected to demethylation and oxidation occurred but a little. The gaseous products were thus generated as a result of coal oxidation and methanation by water.

\section{Conclusion}

Nowadays, the search for new feedstocks of tar pitches is becoming mandatory to cover the growing demand in the aluminum industry. In the present study, supercritical fluid extraction of sapropelic and brown coals was studied to extract bitumen which can serve as an alternative feedstock for pitch production.

It was found that Budagovsky sapropelic coal gave the highest yield of toluene extract (up to 83\%) which was enriched in hydrogen, close to heavy oil fractions. Among the brown coals, Chaidakh coal showed higher reactivity compared to Borodino and Kangalas coals. For all coals, addition of small amounts of $\mathrm{H}$-donor ethanol or tetralin co-solvent to toluene fluid greatly improved extract yield, with the gas yield being small.

The experiments provide evidence that in the case of two component solvents containing H-donor co-solvent, it was not essential for the extracting fluid to be above its critical pressure to be effective. Thus, the effect of solvent composition can be manipulated to optimize the supercritical process by reducing the severity of the extraction conditions. The extract produced can be utilized by using traditional tar pitch processing technology: Distillate fractions can be used for motor-fuel production; and the non-volatile residue is a pitch-like product. The composition and binding properties of pitch like product need to be evaluated to make definite conclusion concerning its applicability for anode production.

Water, on the other hand, showed specific behavior in its interaction with coals. The conversion of coals with supercritical water can be considered as a promising method for the production of fuel gases and liquids as well, with the selectivity dependent on temperature. The production of pitch-like feedstock in this case should be integrated with the advanced IGCC technology based on the application of supercritical water with novel thermodynamic cycle power generation (Ding et al., 2014; Bermejo et al., 2004; Guo and Jin, 2013; Guo et al., 2015).

\section{Acknowledgement}

The work was supported by the Federal Target Program "Research and development on the priority directions of development of the scientific technological complex of Russia for 2014-2020", Action 1.3 "Carrying out the applied research directed towards the creation of advanced scientific-technological potential for the development of branches of economy" (the Agreement No. 14.578.21.0005 of 05.06.2014, unique identifier of applied researches (project) RFMEFI57814X0005).

\section{Author's Contributions}

Peter Nikolayevich Kuznetsov: Designed the plan of experiments, supervised the research and wrote the manuscript.

Svetlana Mikhaylovna Kolesnikova and Anastasia Valerievna Kazbanova: Participated in all experiments of the supercritical extraction of coal, analyzed the coals and the products of extraction.

Ludmila Ivanovna Kuznetsova: Executed analysis of experimental data and contributed to the writing of the manuscript.

\section{Ethics}

The authors have no conflicts of interest in the development and publication of current research.

\section{References}

Adschiri, T., S. Tanaka, S. Abe and K. Arai, 1996. A new two-stage process for supercritical fluid extraction of coal with tetralin pretreatment. Fuel, 75: 1124-1128. DOI: 10.1016/0016-2361(96)00050-6

Bermejo, M.D., M.J. Cocero and F. Fernandez-Polanco, 2004. A process for generating power from the oxidation of coal in supercritical water. Fuel, 83: 195-204. DOI: 10.1016/S0016-2361(03)00256-4

Cheng, X., G. Li, Y. Peng, S. Song and X. Shi et al., 2012. Obtaining needle coke from coal liquefaction residue. Chem. Technol. Fuels Oils, 48: 349-355. DOI: 10.1007/s10553-012-0379-3

Ding, N., R. Azargohar, A.K. Dalai and J.A. Kozinski, 2014. Catalytic gasification of glucose to $\mathrm{H}_{2}$ in supercritical water. Fuel Process. Technol., 127: 33-40. DOI: 10.1016/j.fuproc.2014.05.014 
Garcia, R., A. Arenillas, F. Rubiera and S. Moinelo, 2004. Supercritical gas extracts (toluene, ethanol, THF) from low-quality coals: On the search of new precursors for carbon materials. Fuel Process. Technol., 86: 205-222.

DOI: 10.1016/j.fuproc.2004.03.002

Guo, L. and H. Jin, 2013. Boiling coal in water: Hydrogen production and power generation system with zero net $\mathrm{CO}_{2}$ emission based on coal and supercritical water gasification. Int. J. Hydrogen Energy, 38: 12953-12967.

DOI: 10.1016/j.ijhydene.2013.04.089

Guo, L., H. Jin and Y. Lu, 2015. Supercritical water gasification research and development in China. J. Supercritical Fluids, 96: 144-150. DOI: 10.1016/j.supflu.2014.09.023

Han, S., X. Yan, B. Wang and J. Zhang, 2015. Coliquefaction of lignite and biomass in sub-critical water with ionic liquid. CIESC J., 66: 1476-1483. DOI: $10.11949 /$ j.issn.0438-1157.20141357

Hourcade, M.L., C. Torrente and M.A. Galan, 2007. Study of the solubility of kerogen from oil shales (Puertollano, Spain) in supercritical toluene and methanol. Fuel, 86: 698-705.

DOI: $10.1016 /$ j.fuel.2006.07.013

$\mathrm{Hu}, \mathrm{H}$. , S. Guo and K. Hedden, 1998. Extraction of lignite with water in sub- and supercritical states. Fuel Process. Technol., 53: 269-277. DOI: $10.1016 / \mathrm{S} 0378-3820(97) 00057-\mathrm{X}$

Kashimura, N., J. Hayashi and T. Chiba, 2004. Degradation of a Victorian brown coal in subcritical water. Fuel, 83: 353-358. DOI: $10.1016 /$ j.fuel.2003.07.002

Kolak, J.J. and R.C. Burruss, 2014. The use of solvent extractions and solubility theory to discern hydrocarbon associations in coal, with application to the coal-supercritical $\mathrm{CO}_{2}$ system. Organic Geochem., 73: 56-69.

DOI: 10.1016/j.orggeochem.2014.05.002

Kuznetsov, P.N., L.I. Kuznetsova, J. Bimer, P. Salbut and R. Gruber et al., 1997. Quantitative relation between the macromolecular characteristics of brown coal and its reactivity in conversion with tetralin. Fuel, 76: 189-193.

DOI: $10.1016 / \mathrm{S} 0016-2361(96) 00172-\mathrm{X}$
Lifshits, S.K., O.N. Chalaya and V.A. Kashirtsev, 2012. Extraction of brown coal with carbon dioxide at supercritical parameters. Solid Fuel Chem., 46: 85-89. DOI: $10.3103 / \mathrm{S} 0361521912010090$

Owczarek, I. and K. Blazej, 2003. Recommended critical temperatures. Part I. Aliphatic hydrocarbons. J. Phys. Chem. Ref. Data, 32: 1411-1411. DOI: $10.1063 / 1.1556431$

Park, J.H., Y.O. Joung and S.D. Park, 2007. Sulfur removal from coal with supercritical fluid treatment. Korean J. Chem. Eng., 24: 314-318. DOI: $10.1007 / \mathrm{s} 11814-007-5043-y$

Perez, M., M. Granda, R. Santamaria, J.A. Vina and R. Menendes, 2003. Formulation, structure and properties of carbon anodes from coal tar pitch/petroleum pitch blends. Light Metals, 4: 495-501.

Rahman, M., A. Samanta and R. Gupta, 2013. Production and characterization of ash-free coal from low-rank Canadian coal by solvent extraction. Fuel Process. Technol., 115: 88-98. DOI: $10.1016 /$ j.fuproc. 2013.04.008

Sun, Y., X. Wang and T. Feng, 2014. Evaluation of coal extraction with supercritical carbon dioxide/1methyl2-pyrrolidone mixed solvent. Energy Fuels, 28: 816-824. DOI: $10.1021 / \mathrm{ef} 401682 \mathrm{~g}$

Torrente, M.C. and M.A. Galán, 2010. Extraction of kerogen from oil shale (Puertollano, Spain) with supercritical toluene and methanol mixtures. Industrial Eng. Chem. Res., 50: 1730-1738. DOI: $10.1021 /$ ie 1004509

Wu, B., H. Hu, Y. Zhao, L. Jin and Y. Fang, 2009. XPS analysis and combustibility of residues from two coals extraction with sub- and supercritical water. J. Fuel Chem. Technol., 37: 385-392. DOI: 10.1016/S1872-5813(10)60001-1

Zhao, W., W.J. Xu, X.J. Lu, C. Sheng and S.T. Zhong et al., 2010. Preparation and property measurement of liquid fuel from supercritical ethanolysis of wheat stalk. Energy Fuels, 24: 136-144. DOI: $10.1021 / \mathrm{ef} 900521 \mathrm{k}$ 